RU Особенности организации учебной коммуникации в условиях применения технологии виртуальной реальности

\author{
Жигалова О. П.
}

Аннотация. Цель исследования - выявить особенности организации учебной коммуникации в условиях применения технологии виртуальной реальности. Автором выделены ключевые проблемы, с которыми может столкнуться педагог в процессе организации учебной деятельности обучающихся с использованием технологии виртуальной реальности. Научная новизна состоит в описании компонентов учебной коммуникации в условиях применения технологии виртуальной реальности. В результате выделены особенности организации процесса обучения с применением VR-средств обучения, обоснована важность учебной коммуникации, определены условия и особенности ее организации.

\title{
EN Features of Organising Educational Communication in the Setting of Using the Virtual Reality Technology
}

\author{
Zhigalova O. P.
}

\begin{abstract}
The study aims to determine the features of organising educational communication in the setting of using the virtual reality technology. The author identifies the key issues that a teacher may face in the process of organising students' educational activities using the virtual reality technology. Scientific novelty lies in describing the components of educational communication in the setting of using the virtual reality technology. As a result, the features of organising the educational process using VR learning tools have been identified, the importance of educational communication has been substantiated, the conditions and features of its organisation have been determined.
\end{abstract}

\section{Введение}

Актуальность темы исследования обусловлена активным проникновением технологии виртуальной реальности в образовательную сферу. VR-средства обучения рассматриваются в качестве эффективных инструментов для организации тестирования, формирования устойчивой модели поведения или освоения алгоритма деятельности в условиях реализации персонализированного обучения и организации обучения в режиме онлайн (Вишневский, Гохберг, Дементьев, 2021; Jenson, Diane, 2012; Жигалова, 2021b). Технология виртуальной реальности рассматривается нами как комплекс аппаратно-программных средств, обеспечивающих иммерсивное погружение пользователя в виртуальную среду. Отсутствие единых стандартов разработки и использования технологии виртуальной реальности в образовательных целях способствует проникновению образовательного контента в реальную практику. Вопрос об использовании технологии виртуальной реальности в сфере образования является дискуссионным. Данный вопрос обсуждается в среде педагогов, психологов, психофизиологов, представителей медицинской сферы. В зоне компетенций педагогов-исследователей находятся задачи, связанные с определением характера и условий организации педагогического взаимодействия между педагогом и обучающимися в ситуации использования VR-средств (Роберт, 2020). К ключевым из них можно отнести следующие: определить содержание учебных задач для выполнения в среде виртуальной реальности, которые необходимо поставить педагогу перед обучающимися; раскрыть роль педагога при организации учебного процесса в условиях использования VR-технологий; выявить характер учебной коммуникации и ее целевые ориентиры в данных условиях.

В рамках исследования поставлены следующие задачи:

- выделить основные аспекты организации процесса обучения в условиях применения технологии виртуальной реальности и обосновать ключевую роль учебной коммуникации; 
- уточнить понятие «учебная коммуникация» и дать характеристику учебной коммуникации в условиях применения технологии виртуальной реальности.

Основу теоретического исследования составляют методы системного анализа, метод умозаключений, приемы обобщения и логического вывода. Основные идеи средо-ориентированного подхода к обучению определяют методологическую базу исследования. Среда виртуальной реальности рассматривается в качестве ресурса для формирования эмоционально насыщенного опыта деятельности у обучающихся.

Практическая значимость данной публикации состоит в выделении некоторых аспектов педагогического взаимодействия в условиях применения VR-технологий; в выявлении ключевых характеристик учебной коммуникации в отмеченных условиях. Полученные результаты предназначены для использования на этапе проектирования методических приемов, связанных с применением VR-средств обучения в реальной образовательной практике.

\section{Организация процесса обучения в условиях применения VR-технологии на основе учебной коммуникации}

Технология виртуальной реальности рассматривается в контексте перспективных интегрированных обучающих систем, связанных с использованием прогрессивных приемов, реализующихся в новых условиях (Корнилов, 2019). Данная технология позволяет смоделировать комфортные условия для получения новых знаний (Малий, Медведев, Маркова, 2019). Среди основных преимуществ, связанных с использованием технологии виртуальной реальности в образовании, выделяют: высокая наглядность учебного материала, безопасность условий обучения, вовлеченность обучающихся в учебный процесс, абсолютная фокусировка внимания обучающихся в рамках выполняемой учебной задачи, экономичность в организации учебного процесса (Белянская, Костина, Гладких, 2019; Савчук, 2013; Сальникова, 2012). Использование технологии виртуальной реальности, по мнению отдельных авторов, позволяет вывести учебный процесс на новый уровень организации обучения (Дубова, Колесникова, 2021). Обучение осуществляется на более качественном уровне за счет погружения в среду и включения сенсорных механизмов в событийное или контекстное обучение. Данный подход считается наиболее эффективным на этапе организации практической деятельности обучающихся с использованием электронной формы обучения или дистанционных технологий. К качественным характеристикам данного уровня организации учебного процесса следует отнести следующие: персонализированная обратная связь; автоматизация системы фиксации и обработки объективных показателей, отражающих результаты обучения на расстоянии (время, количество, точность выполнения действий, успешность выполнения и т.д.); управление сценариями обучения в условиях удаленной работы; создание уникальных возможностей для организации работы обучающихся в домашних условиях (Пискунова, Побокин, 2021; Maheshwari, Maheshwari, 2020; Zhai, 2021).

Таким образом, обсуждается вопрос о включении технологии виртуальной реальности в образовательный процесс. Ряд исследований подтверждают, что уровень подготовки обучающихся с использованием данных средств не ниже традиционных способов обучения (Преображенская, Карпук, Ткаченко, 2021). На данный момент активно разрабатываются и рекомендуются к использованию учебные тренажеры для системы профессионального образования (Жигалова, 2021a). Следует заметить, что проектирование программных средств учебного назначения происходит в условиях отсутствия стандартизированных процедур разработки, норм и правил использования цифровых технологий. В результате возникает ряд проблем, связанных не только с соблюдением эргономических и санитарно-гигиенических норм и правил использования VR-средств в учебном процессе, но и с организацией деятельности обучающихся в условиях применения технологии виртуальной реальности. Отметим ключевые из них: создание учебной ситуации в условиях применения VR-технологий; организация учебного взаимодействия в условиях использования VR-средств.

Организация учебной ситуации в условиях использования VR-средств происходит с учетом основных аспектов применения средо-ориентированного подхода в обучении. В рамках данного подхода обучаемый рассматривается в контексте агента, включенного в активную коммуникацию со средой и действующего в условиях реактивного постоянно изменяющегося динамического окружения. Процесс обучения с использованием VR-технологий характеризуется набором признаков. Процесс является событийным (ситуационным), т.е. разворачивается в условиях виртуального события или ситуации; процесс обучения не является линейным, т.к. учебный материал предъявляется непоследовательно, отсутствует линейный сценарий изучения; процесс обучения осуществляется в визуально-насыщенной учебной среде, которая расширяет реальное образовательное пространство. С. Ф. Сергеев (2009) в своей работе указывает на основные характеристики учебной среды в условиях применения VR-технологий: модальность и дискретность. Механизм взаимодействия со средой, как правило, не ограничен жесткими правилами, имеет гибкую структуру, которая зависит от поведения обучающегося в среде. Среда представляет собой набор связанных трехмерных виртуальных пространств, которые сменяют друг друга в зависимости от действий пользователя.

Способ и приемы взаимодействия обучающихся с VR-средствами следует рассматривать в единстве перцептивной, интерактивно-инструментальной, интеллектуально-преобразующей деятельности обучающихся (Носкова, Павлова, 2019). Данный подход обоснован особенностями среды виртуальной реальности, которая 
обеспечивает иммерсивное погружение, интерактивность за счет взаимодействия с 3D-объектами, определенную свободу действий.

Роль педагога в среде, опосредованной VR-технологиями, становится многогранной. Педагог обеспечивает сопровождение деятельности обучающихся, выступая в роли проводника. Выступая в данной роли, педагог решает задачи, связанные с донесением до обучающихся информации об использовании манипуляторов управления и виртуальных инструментов обеспечения деятельности. Помимо этого, педагог создает условия для смысловой ориентации обучающихся в процессе выполнения учебных задач с использованием VR-средств. Смысловая ориентация осуществляется на уровне идентификации виртуального окружения и его элементов; на уровне выполнения действий и осуществления манипуляций с виртуальным инструментарием; на уровне понимания и осознания результатов деятельности. С. Ф. Сергеев (2011) поднимает вопрос о том, что в ситуации использования VR-технологий педагог выступает в роли мотиватора (фасилитатора), действия которого направлены на усиление продуктивности взаимодействия с элементами среды виртуальной реальности, оптимизацию результатов обучения.

Таким образом, учебная коммуникация является основным средством взаимодействия педагога и обучающихся в условиях применения VR-средств обучения. Средствами учебной коммуникации педагог задает параметры обучения, определяет условия выполнения учебной задачи, корректирует ход деятельности обучающихся, обеспечивает смысловую ориентацию и создает условия для осознания обучающимися результатов деятельности в среде виртуальной реальности.

\section{Содержание учебной коммуникации в условиях применения VR-технологии}

В педагогической литературе общение рассматривается как основная форма педагогического взаимодействия (Ядровская, 2009). В процессе общения осуществляется управляемое познание, направленное на усвоение социального опыта или овладение приемами деятельности; создается синергетический эффект, который способствует расширению интеллектуальных возможностей личности (Симонова, 2018). Обмен информацией в процессе учебного взаимодействия может осуществляться в реактивной или проактивной форме. В реактивной форме педагог реагирует на запрос информации со стороны обучающегося, в проактивной форме педагог предвосхищает ситуацию и информирует обучающегося заблаговременно о содержании или условиях организации учебной деятельности. Профессиональная интерсубъективность, как специфическая черта педагога предвосхищать состояние и поведение обучающегося, обеспечивает эффективность учебной коммуникации (Розина, 2003). Учебная коммуникация есть непрерывный процесс, во время которого педагог и обучающийся, находясь в едином коммуникативном пространстве, приходят к общим, аналогично понимаемым смыслам с использованием различных средств общения (Mottet, Richmond, McCroskey, 2006). Вербальное или невербальное реагирование на реплики друг друга следует рассматривать как факторы обеспечения эффективной учебной коммуникации.

В структуре учебной коммуникации выделяют ключевые элементы: коммуникативный процесс, коммуникативное пространство, коммуникативное событие, коммуникативная задача (Яковлев, 2006). В условиях реализации субъект-субъектного взаимодействия учебно-педагогическая коммуникация направлена на решение задач, связанных с передачей учебной информации, с побуждением к действию, с осмыслением результатов деятельности. Педагог в процессе обучения прибегает к речевым приемам для выражения отношения к ситуации (эмотивная функция), для привлечения внимания (конативная функция), для сосредоточения внимания обучающихся на содержании произносимого (Чибаков, 2020). Данные функции коммуникации в условиях организации учебного процесса ориентированы на побуждение обучающихся к деятельности и стимулирование к саморазвитию (Зелеева, 2012).

В условиях применения VR-технологий учебная коммуникация характеризуется рядом особенностей, которые обусловлены тем, что обучающийся находится в среде виртуальной реальности, а педагог - в реальном пространстве (Kim, Nah, Oh et al., 2019). Педагог обеспечивает безопасность деятельности обучающихся как в реальной среде, в которой они присутствуют физически, так и в среде виртуальной реальности, в которой организован учебный процесс. Обучающиеся, находясь в среде виртуальной реальности, не могут самостоятельно фиксировать изменения в реальной обстановке и, соответственно, реагировать на них. Педагог должен учитывать характер поведения обучающихся в реальной среде (в пространстве учебного класса): устойчивое/неустойчивое положение, безопасность передвижения, безопасность выполнения действий и т.д. В процессе обучения педагог должен фиксировать модель поведения обучающихся в ходе выполнения учебной задачи (в среде виртуальной реальности): успешность/неуспешность в выполнении действий, порядок выполнения действий, точность выполнения действий и т.д. Учебная коммуникация выстраивается с учетом информации, зафиксированной педагогом в реальной среде и среде виртуальной реальности. Коммуникативное пространство педагога расширяется. Обучающиеся в процессе организации учебной коммуникации опираются только на информацию, полученную в среде виртуальной реальности.

В окружении педагога и обучающихся нет единого аудиовизуального поля. Процесс коммуникации осложнен в силу того, что педагог, находясь в реальной среде, должен осуществлять управление коммуникативным процессом с опорой на визуальное 3D-окружение обучающегося. Это приводит к ограничению 
процесса организации учебной коммуникации: педагог не может использовать невербальные способы общения. Не представляется возможным дополнение процесса учебной коммуникации эмоциональными смыслами, усиливающими эффект взаимодействия, за счет применения таких невербальных средств, как жест или улыбка. Основным каналом организации учебной коммуникации выступает аудиоканал. Обучающиеся, находясь в среде виртуальной реальности, для обращения к педагогу используют устный запрос, могут поднять руку или покачать головой. Учебная коммуникация в среде, как правило, представляет собой диалог в формате вопрос-ответ, ориентированный на интерпретацию виртуального средового окружения обучающихся. Педагогу предстоит осуществлять активный диалог с обучающимся, связанный с оказанием консультативной помощи; предполагающий включение обучающегося в учебную деятельность и его ориентацию в зоне «учебных смыслов» в условиях среды виртуальной реальности. Вопросы со стороны педагога ориентированы на выявление уровня самочувствия обучающегося, на определение степени готовности к реализации деятельности, на понимание смысла деятельности и планируемого результата. Рекомендации со стороны педагога ориентированы на включение обучающегося в учебную виртуальную среду; на сопровождение обучающегося в процессе выполнения конкретных действий или наблюдаемой ситуации. Ситуация в среде виртуальной реальности, в которой оказывается обучающийся, обусловливает содержание учебной коммуникации. Ситуативные действия нельзя описать в виде набора инструкций для педагога. Они происходят в рамках конкретной ситуации коммуникативного взаимодействия. Основной упор педагогу следует делать на речевые инструкции и комментирование хода деятельности обучающихся в среде виртуальной реальности. Таким образом, коммуникативное событие обусловлено визуальным 3D-окружением обучающегося.

Учебная информация в среде виртуальной реальности представляет собой содержательный контент в 3D-визуализированном формате, дополненном звуковыми или текстовыми инструкциями. Ключевым процессом, ориентированным на работу с визуализированным контентом в среде виртуальной реальности, выступает процесс интерпретации 3D-объектов и 3D-сцен. В среде виртуальной реальности обучающийся оперирует виртуальными образами, с которыми отсутствует тактильный контакт, с которыми нельзя выполнить прямое действие. Интерпретация виртуального окружения, идентификация 3D-объектов, манипуляция с объектом - ключевые действия, которые выполняет обучающийся в среде. Все действия выполняются с использованием «виртуальных рук». «Виртуальные руки» (имитация реальных рук в среде виртуальной реальности) рассматриваются в качестве основного приема, который используется программистами при создании контента для определения позиции пользователя в виртуальном пространстве. Поэтому они присутствуют во всех средствах учебного назначения, где предполагается выполнение пользователем определенного набора действий. В процессе выполнения учебной задачи обучающийся может использовать только виртуальные инструменты. В среде виртуальной реальности обучающиеся лишены возможности фиксировать учебную информацию, например, как это они делают в реальной среде, записывая в тетради. Они должны ориентироваться только на визуализированные образы выполненных действий. Таким образом, коммуникативная задача отражает характер взаимодействия с объектами среды виртуальной реальности, способы перемещения и ориентации, приемы интерактивного взаимодействия с объектами среды с использованием «виртуальных рук».

В условиях применения технологии виртуальной реальности изменяются такие компоненты учебной коммуникации, как коммуникативное пространство, коммуникативный процесс, коммуникативное событие, коммуникативная задача.

\section{Заключение}

В заключение можно сделать следующие выводы о том, что процесс обучения становится событийным, разворачивается не по линейному сценарию, происходит в условиях визуально-насыщенной учебной среды, при этом учебная коммуникация становится основным и единственным средством взаимодействия педагога с обучающимися.

В условиях применения технологии виртуальной реальности изменяются отдельные компоненты учебной коммуникации:

- коммуникативное пространство расширяется и дополняется средой виртуальной реальности;

- коммуникативный процесс ограничивается и осуществляется только в форме диалога. Вербальный способ коммуникации становится основным в процессе взаимодействия между педагогом и обучающимися;

- коммуникативное событие зависит от виртуального окружения обучающегося;

- коммуникативная задача наполняется новым содержанием, которое отражает интерактивное взаимодействие с объектами виртуального окружения.

Изменение составляющих учебной коммуникации затрагивает процесс педагогического взаимодействия педагога и обучающихся и требует детального изучения.

Перспективные направления в данном исследовании связаны с определением оптимального содержания учебной коммуникации в условиях реактивного и проактивного способов взаимодействия педагога с обучающимся; характера учебной коммуникации, способствующей успешному выполнению учебных задач в среде виртуальной реальности. 


\section{Финансирование | Funding}

RU

Публикация подготовлена в рамках реализации государственного задания (проект № 0657-2020-0009).

The reported study was conducted as a part of the state assignment (project number 0657-2020-0009).

\section{Источники | References}

1. Белянская Е. И., Костина И. Б., Гладких Ю. П. VR как часть образовательного процесса // COLLOQUIUMJOURNAL. 2019. № 28-06 (52).

2. Вишневский К. О., Гохберг Л. М., Дементьев В. В. Цифровые технологии в российской экономике / под ред. Л. М. Гохберга; НИУ «Высшая школа экономики». М.: НИУ ВШЭ, 2021.

3. Дубова А. А., Колесникова Е. С. Роль технологий виртуальной реальности в сфере образования // Наукосфера. 2021. № 1-2.

4. Жигалова О. П. Технология виртуальной реальности в профессиональном образовании: основные тенденции // Информация и образование: границы коммуникаций INFO’21: сб. науч. тр. № 13 (21) / под ред. А. А. Темербековой, И. В. Соловкиной. Горно-Алтайск: БИЦ ГАГУ, 2021a.

5. Жигалова О. П. Учебные симуляторы в системе профессионального образования: педагогический аспект // Азимут научных исследований: педагогика и психология. 2021b. № 1 (34).

6. Зелеева В. П. Коммуникативное событие и его анализ в образовательном пространстве вуза // Образование и саморазвитие. 2012. № 2 (30).

7. Корнилов Ю. В. Иммерсивный подход в образовании // Азимут научных исследований: педагогика и психология. 2019. № 1 (26).

8. Малий Д. В., Медведев П. Н., Маркова М. Г. К вопросу об использовании иммерсивных технологий в образовательном процессе // Преемственность в образовании. 2019. № 22 (06).

9. Носкова Т. Н., Павлова Т. Б. Взаимодействие с цифровыми ресурсами: продуктивность образовательной деятельности // Человек и образование. 2019. № 3 (60).

10. Пискунова М. Д., Побокин П. А. Отношение студентов к обучению с использованием программ виртуальной реальности // Ярославский педагогический вестник. 2021. № 2 (119).

11. Преображенская С. В., Карпук В. А., Ткаченко Д. П. Включение VR-технологий в образовательный процесс: возможности и ограничения // Новые психологические исследования. 2021. № 2.

12. Роберт И. В. Направления развития информатизации отечественного образования периода цифровых информационных технологий // Электронные библиотеки. 2020. T. 23. Вып. 1-2. URL: https:/elbib.ru/ article/view/578

13. Розина И. Н. Общение в единой образовательной среде или учебная компьютерно-опосредованная коммуникация // Образовательные технологии и общество. 2003. № 2.

14. Савчук В. В. Медиафилософия: приступ реальности. СПб.: Изд-во РХГА, 2013.

15. Сальникова Е. В. Феномен визуальности и эволюция визуальной культуры: автореф. дисс. ... д. культ. М., 2012.

16. Сергеев С. Ф. Методология проектирования тренажеров с иммерсивными обучающими средами // Научно-технический вестник Санкт-Петербургского государственного университета информационных технологий, механики и оптики. 2011. № 1 (71).

17. Сергеев С. Ф. Обучающие и профессиональные иммерсивные среды. М.: Народное образование, 2009.

18. Симонова М. М. Основные модели коммуникации и их применение в учебном процессе // Наука и школа. 2018. № 4.

19. Чибаков А. С. Диалоговые взаимодействия в учебном процессе учреждения среднего профессионального образования // The Scientific Heritage. 2020. № 57-4.

20. Ядровская М. В. Моделирование педагогического взаимодействия // Образовательные технологии и общество. 2009. № 3 .

21. Яковлев И. П. Ключи к общению. Основы теории коммуникаций. СПб.: Авалон; Азбука-классика, 2006.

22. Jenson C. E., Diane M. F. Virtual Reality Simulation: Using Three-Dimensional Technology to Teach Nursing Students // CIN: Computers, Informatics, Nursing. 2012. № 6.

23. Kim H., Nah S., Oh J., Ryu H. VR-MOOCs: A Learning Management System for VR Education // 2019 IEEE Conference on Virtual Reality and 3D User Interfaces (VR). Osaka, 2019. DOI: 10.1109/VR.2019.8798106

24. Maheshwari I., Maheshwari P. Effectiveness of Immersive VR in STEM Education // 2020 Seventh International Conference on Information Technology Trends (ITT). Abu Dhabi, 2020. DOI: 10.1109/ITT51279.2020.9320779

25. Mottet T. P., Richmond V. P., McCroskey J. P. Handbook of Instructional Communication. Rhetorical and Relational Perspectives. N. Y.: Routledge, 2006.

26. Zhai H. The Application of VR Technology in Preschool Education Professional Teaching // 2021 2nd International Conference on Artificial Intelligence and Education (ICAIE). Dali, 2021. DOI: 10.1109/ICAIE53562.2021.00072 


\section{Информация об авторах | Author information}

RU Жигалова Ольга Павловна ${ }^{1}$, к. пед. н., доц.

${ }^{1}$ Дальневосточный федеральный университет, г. Владивосток

EN Zhigalova Olga Pavlovna ${ }^{1}, \mathrm{PhD}$

${ }^{1}$ Far Eastern Federal University, Vladivostok

${ }^{1}$ zhigalova.op@dvfu.ru

\section{Информация о статье | About this article}

Дата поступления рукописи (received): 05.01.2022; опубликовано (published): 28.02.2022.

Ключевые слова (keywords): учебная коммуникация; технология виртуальной реальности; VR-средства обучения; цифровая образовательная среда; educational communication; virtual reality technology; VR learning tools; digital educational environment. 